ENTRE FRESTAS E ARESTAS:

LITERATURA E A MÚSICA NO CONTO MACHADIANO

\author{
Igor Alexandre Barcelos Graciano Borges* \\ Danglei de Castro Pereira*
}

RESUMO: O presente trabalho analisa indícios de diálogo entre literatura e música no conto intitulado: "Trio em lá menor", do escritor Machado de Assis. A análise tem como objetivo entender como elementos da teoria musical, como, por exemplo, as nomenclaturas e os conceitos, assim como as ideias de resolução de campo harmônico, se entrelaçam à escrita do texto, ultrapassando a ideia da mera justificativa do andamento de leitura do conto, constituindo-se parte integrante do material textual. A relação entre as artes irmãs proporciona um caleidoscópio de possibilidades, nos parece que o autor fez uso de ideias de resolução de campo harmônico, entre outras do universo musical, para compor, ou melhor, escrever seu texto, criando uma atmosfera um pouco movediça, devido ao olhar cauteloso do escritor no que concerne ao diálogo e, na medida em que as questões amorosas vão se resolvendo seria, hipoteticamente, como se o campo harmônico fosse sendo resolvido, uma espécie de coadunação rizomática musico-literária.

PALAVRAS-CHAVES: Literatura; Música; Machado de Assis; Conto.

"Poets and musicians are members of one church, Related in the most intimate way: for the secret of word and tone is one and the same".

\title{
Introito
}

E.T.A Hoffman

O presente trabalho analisa indícios de diálogo entre literatura e música no conto intitulado: "Trio em lá menor", do escritor Machado de Assis ${ }^{8}$. A análise tem como objetivo entender como elementos da teoria musical, como, por exemplo, as várias nomenclaturas,

\footnotetext{
* Doutorando pela Universidade de Brasília (UnB). Trabalha com a figura da Ironia Romântica na obra poética do escritor Luiz Gama. Mestre em Letras, na linha de Historiografia Literária, pela Universidade Estadual do Mato Grosso do Sul (Uems).

** Professor da Universidade de Brasília (UnB). Doutor em Letras pela UnB. Fez estágio de pós-doutorado em literatura brasileira pela Universidade de São paulo (USP).

${ }^{8}$ Utilizaremos também, para nos referirmos ao escritor, apenas Machado.
} 
conceitos e ideias de resolução de campo harmônico, se entrelaçam à escrita do texto, ultrapassando a ideia da mera justificativa do andamento de leitura do conto, constituindo parte integrante do material textual. Assim sendo, o ponto principal constitui-se em destacar o entrelaçamento que Machado de Assis fez entre as duas artes - a literatura e a música, em outras palavras, realizar uma análise das relações das artes irmãs encontradas no conto machadiano, pensando principalmente, nas estruturas internas do conto, ou seja, no emaranhamento das duas linguagens.

Nesta esteira, em certa medida, nos parece que o autor fez uso de ideias de resolução de campo harmônico para compor, ou melhor, escrever seu texto, criando uma atmosfera e um esqueleto organizado a favor do diálogo entre das artes. Por esta perspectiva, percebemos que, de acordo que as questões amorosas vão se resolvendo, assemelhasse ao processo de resolução de um campo harmônico musical, uma espécie de coadunação em que estão envolvidos; o diálogo entre as artes irmãs, o roteiro do conto e o campo harmônico com as nomenclaturas musicais, abrindo possibilidades que ultrapassam o mero andamento de leitura, principalmente, quando se leva em consideração a questão do ritmo, elemento polivalente das artes. Em outras palavras, o conto está impregnado de elementos musicais, tanto em sua estrutura, como também, nas ideias de desenvolvimento e de leitura.

As hipóteses suscitadas para esclarecer as inquietações são, em primeiro lugar, a relação das terminologias Adagio cantabile, Allegro ma non troppo, Allegro appassionato e Minueto que estão entrelaçados, diretamente, ao enredo e consequentemente, os elementos musicais vivem a partir do texto literário, uma quase vida "parasitária", ou intertextual, como também, transtextual ${ }^{9}$. Em segundo lugar, percebe-se que, existe um leitmotiv, a saber, a inde-

\footnotetext{
${ }^{9}$ A terminologia "inter" e "trans" textual foi refletida de forma a realizar as relações que condicionam o olhar de diálogo entre uma ou mais artes, mas, também, a relação de maior espessura. Algo que, talvez, possa ser entendido, no que concerne a relação entre as artes, como; o profundo diálogo travado desde o Medievo.
} 
cisão da personagem principal, que se torna elemento preponderante e que liga a personagem a sua sina/destino, algo aproximado ao que chamaríamos de ironia ${ }^{10}$ conjectural, e no que diz respeito a música uma quarta aumentada ou uma quinta diminuta ${ }^{11}$, falaremos disso mais adiante.

A partir do mencionado, percebe-se que, o conto comporta não somente uma representação artística, mas duas. Por mais que uma se sobressaia a outra, observa-se que, o escritor teve a dedicação e a sensibilidade de colocar duas artes dialogarem dentro de uma mesma obra, ou melhor, gênero. A estrutura, do gênero mencionado, ou seja, o conto, possui contornos e características, cria barreiras que delineiam até que ponto pode-se explorar, ou até que ponto dá para se pensar nas relações dentro a estrutura, tanto a musical quanto a literária, algo realizado com perícia. Não é à toa que admitimos a profunda pluralidade da obra machadiana. A este respeito, Veríssimo (1954) destaca que, a genialidade de Machado de Assis o fez umas das principais figuras da literatura brasileira, e que se consolidam nele a última geração romântica, com seu refinado olhar ${ }^{12}$ diante a sociedade, atravessando vários momentos e correntes literárias, as quais ele aderiu parcialmente, mas, não por completo.

Machado de Assis contribuiu, imensamente, para pensarmos a arte literária e a musical não como universos estanques, ou separados, mas sim, como mundos que em várias situações amalgamam-se. Para além da abordagem tradicional de pensar a arte, tanto a literária como a musical unilateralmente, entendemos que ele utiliza, de forma espectral, a

\footnotetext{
${ }^{10}$ Por mais que a ironia esteja assentada de forma sutil, não devemos nos deixar enganar, pois, ainda se trata da ironia machadiana. Por meio da visão irônica do autor, se torna possível, por exemplo, entendemos referências a aspectos históricos, sociológicos, estéticos e culturais de sua época.

${ }^{11}$ No processo de contração e relaxamento que encontramos na arte musical, estes dois intervalos se caracterizam como os que mais induzem o músico a realizar a resolução (levando que a sensível suba a tônica), se apresentando como quase que obrigatória, e no que diz respeito a Harmonia tradicional, obrigatória. Para maiores informações vide: Harmonia Tradicional, de Paul Hindemith, ou, Harmonia \& Improvisação de Almir Chediack.
}

${ }^{12}$ Olhar irônico, do nosso ponto de vista. 
forma sonata no conto "Trio em Lá menor", a construção dialógica do conto abre o procedimento da mescla dos gêneros, fato difundido pelo Romantismo, no aspecto da liberdade de criação, vinculado também a questão do poder imaginativo.

Este processo em questão, se alimenta da construção de uma estética mais oxigenada e moderna, como também, reflete profundamente, a respeito do poder da imaginação e na construção do olhar o mundo através dos olhos do artista. E assim, tomando o conto como ponto de partida, se torna possível vislumbrar o diálogo que outrora se estabelecia com maior estabilidade, ou seja, da música na literatura e vice-versa. É notável, neste sentido, que, Machado de Assis possuía o conhecimento no que diz respeito as formas musicais, arriscaríamos dizer, observando a envergadura do escritor, que, entendia também a estética musical de sua época.

Nesta óptica, o autor possui uma sensibilidade não somente para o universo literário, como também, para o musical ${ }^{13}$. Constata-se isso, ao observar-se o conto analisado, como também, alguns outros, como, por exemplo, “Aurora sem dia” (1873), "A chinela" (1875), “O Machete” (1878), “O anel de Polícrates” (1882), “O programa” (1882-1883), "Cantiga de esponsais" (1883), “Cantiga velha” (1883), "Habilidoso” (1885), “O cônego ou A metafísica do estilo” (1885), “Trio em lá menor” (1886), “Um homem célebre” (1888), "Vênus! Divina Vênus!” (1893) e "Um erradio" (1894). ${ }^{14}$

É notável que a força da música está presente nos escritos machadianos. Vale destacar algumas conexões que o autor deixava em seus romances, possibilitando entendermos, que, a música proporcionou recursos, ou a espécie de um caminho, de universo simbólico, ou ainda um diálogo estético, para a escrita machadiana. Em Memorial de Aires, por exemplo, nos deparamos com a seguinte passagem: "a música foi sempre uma das

\footnotetext{
${ }^{13}$ A este respeito temos como pontapé inicial, o pensamento de José Miguel Wisnik, que, em sua obra Sem receita, ensaios e canções, analisa o conto "O machete" de Machado de Assis.

${ }^{14}$ Os títulos os quais fazemos referência constam na obra "Contos de Machado de Assis - Música e Literatura" organizado por João Cezar de Castro Rocha. Nesta obra, os contos, são apresentados de forma cronológica e sistemática, algo que muito nos ajuda a entender esta faceta machadiana. A obra não traz a análise dos textos, propriamente, dito. Entretanto, constrói a corpora de contos machadianos os quais em toda a sua extensão possuem aspectos, temas, citações ou qualquer coisa que o valha, no que diz respeito a Música.
} 
minhas inclinações, e, se não fosse temer o poético e acaso o poético, diria que é hoje das saudades. Se a tivesse aprendido, tocaria agora ou comporia, quem sabe?” (ASSIS, p. 51).

Uma outra bastante cara e representativa, é a que consta em Esaú e Jacó: “A música tinha para ela [Flora] a vantagem de não ser presente, passado ou futuro; era uma coisa do tempo e do espaço, uma idealidade pura" (ASSIS, p. 84), destacamos, também, por exemplo, do conto ao qual analisamos, a saber, "e a música ia ajudando a ficção, indecisa a princípio" (ASSIS, p. 152). Machado possui uma qualidade prodigiosa que é produzir, progressivamente, uma obra que carrega a cada passo um melhoramento em relação à anterior, é importante mencionar isso, devido o trajeto de construção do intelectual. A este respeito Veríssimo assevera que,

Ao contrário de alguns notáveis escritores nossos que começaram pelas suas melhores obras e como que nelas se esgotaram, tem Machado de Assis uma marcha ascendente. Cada obra sua é um progresso sobre a anterior. Ou de própria intuição do seu claro gênio, ou por influência do particular meio literário em que se achou, fosse porque fosse, foi ele um dos raros senão o único escritor brasileiro do seu tempo que voluntariamente se entregou ao estudo da língua pela leitura atenta dos seus melhores modelos. (VERÍSSIMO, 1954. p. 5)

Neste sentido, se torna perceptível, que, estudar uma obra Machadiana é sempre um desafio, devido à qualidade estética, complexidade e qualidade de escrita que ele possuía. O universo machadiano já há algum tempo vem sendo explorado, não é difícil encontrarmos, por exemplo, teses, dissertações, artigos e ensaios a respeito de sua obra. No que diz respeito a música como tema, principal ou secundário, da prosa machadiana, destacamos alguns nomes como, por exemplo, José Miguel Wisnik ${ }^{15}$, Mário Curvello ${ }^{16}$, ou Idelber Avelar ${ }^{17}$ que refletem a respeito de entender como a música influenciou, se apresentou como elemento temático, ou norteador na escrita de algumas obras, principalmente, os

\footnotetext{
${ }^{15}$ Cf.: WISNIK, José Miguel. Machado Maxixe: o caso Pestana. In: Sem receita: ensaios e canções.

${ }^{16}$ Cf.: CURVELlO, Mário. Polcas para um Fausto Suburbano. In: Bosi, A. et al. Machado de Assis: antologia \& estudos.
}

${ }^{17}$ Vide: AVELAR, Idelber. Ritmos do popular no erudito: política e música em Machado de Assis. 
contos machadianos. Machado preocupava-se em entender como funcionava o ofício ${ }^{18}$, pensando neste aspecto, e lendo suas obras é perceptível que ele o fazia bem, não apenas na literatura, como também, de certa forma na música, apesar de não ser músico. Segundo Rocha, Machado compreendeu a diferença entre o "artista" e o "habilidoso", a saber:

Machado de Assis compreendeu a diferença entre o "artista" e o "habilidoso". O motivo é simples, ao menos se revela óbvio após a lição machadiana: "toda arte tem uma técnica, ele aborrecia a técnica, era avesso à aprendizagem, aos rudimentos das coisas”. Em outras palavras, o artista somente se realiza ao trinfar sobre o artesão talentoso, pois, no fundo, o artista não se desenvolve em virtude de seu talento, mas sim ao resistir à facilidade proporcionada pelo dom que possui. Nesse horizonte, recupera-se a etimologia: o artista deve antes de tudo conhecer bem as regras do ofício. (ROCHA, 2008, p. 07)

Ao passo que levamos em consideração a fala de Rocha, admitimos que, Machado buscou relacionar de forma muito interessante os conceitos da música dentro da literatura. Como se imagina, a figura do Machado enquanto escritor é dispensável apresentação, devido à importância. Assim, buscamos de forma sintética destacarmos algumas pequenas questões em relação a figura do escritor. Vale ressaltar que, compreendemos que um regate da fortuna crítica machadiana seria algo interessante para complementar o trabalho, entretanto, enxergamos nossa proposta aqui menos ambiciosa do que ela realmente é, sendo assim, deixaremos tal resgate para trabalhos futuros, que sem sombra de dúvida a terá como componente.

\section{A música e a literatura}

Literatura e música são dois vértices artísticos que se apresentam arraigados na história da humanidade. Ao se agregar as duas temos a manifestação do som e da letra conexos um ao outro, um emaranhado frutífero em possibilidades, uma delas é a canção, entretanto,

18 Ofício não apenas do escritor, como também, do músico. Para melhor entendimento, indicamos a leitura do texto de Idelber Avelar, o qual se encontra disponível online em: http://abralic.idelberavelar.com/txt_19.pdf. 
neste trabalho explorou-se de uma forma uma pouco diferente o diálogo mencionado, pois, elegeu-se um conto para ser analisado. Solange de Oliveira (2002, p. 25) destaca que, "os vários tipos de análises intersemióticos apoiam-se na presunção de uma afinidade básica entre as artes, sem prejuízo da especificidade de cada uma". A autora informa ainda que,

Os textos sobre a história das artes oferecem um bom ponto de partida para o estudo das relações entre os vários sistemas semióticos. Não raro, objetos ligados a uma arte são descritos em termos aplicáveis a outras, sugerindo a existência de elementos comuns. (OLIVERIA, 2002, p. 21)

No caso deste trabalho, o foco se localiza na literatura, especificamente, no conto. Quando se trata da literatura, para o escritor, cada palavra pode ter uma função ímpar dentro do contexto, e a partir das escolhas de palavras, frases, ideias etc., que o autor transmite sua mensagem. Paralelo as características de escritas, se encontram a forma19 com que ele transmite os sentimentos, as críticas, ou as reflexões pela palavra. Utiliza-se de forma singular, ou peculiar, cada preposição, conjunção, advérbio, artigo, morfema, cada figura de linguagem, ou seja, a língua como um todo. Vale destacar que, a partir das relações de diálogo que existe entre as artes, a poesia e a música, podendo extrapolar a literatura como elemento temático-referencial é que encontramos, por exemplo, a canção, se pensarmos com uma roupagem um pouco mais nova, e as Lied, caso o desejo seja buscar raízes que, de certa forma, possibilitaram as ideias que consolidaram a canção.

$\mathrm{O}$ autor tem o poder de transformar e moldar tudo, percebe-se que vários autores, devido as infinitas possibilidades, se utilizam do próprio quotidiano, do contexto histórico da época para caracterizar suas obras, e isso vai além do âmbito social, pois, as características que rodeiam o escritor são incorporadas ao seu senso crítico e aos seus sentimentos. Faraco destaca que,

Em outros termos, é necessário que a consciência artística se libere da prisão da linguagem que se impõem como única e absoluta (...);

\footnotetext{
${ }^{19}$ No que diz respeito à forma, pensamos no conceito do estilo que o escritor utiliza. Como este trabalho não pretende discutir a respeito do estilo machadiano de escrita, o termo mais geral, como, por exemplo, forma, contempla satisfatoriamente o que queremos afirmar.
} 
que se libere da hegemonia aprisionadora do imaginário de uma língua unitária e da língua como mito (isto é, como uma forma absoluta de significar) e se deixe vagar livremente pela heteroglossia. (FARACO, 2009. p. 93)

Por intermédio da heteroglossia um texto é permeado por diversas vozes, ou seja, múltiplas perspectivas individuais e sociais. Pensando na ideia da forma absoluta de significar, encontramos a possibilidade dialógica das várias linguagens que possuímos. M. Bakhtin destaca que a heteroglossia e as múltiplas vozes se constituem a partir dos elementos culturais, das pessoas e da época a qual elas pertencem, ele ainda destaca que, "in actual fact, out of this huge complex of parodically reflected words and voices the ground was being prepared in ancient times"20 (BAKHTIN, 1981, p. 90). Portanto, constitui-se um contexto com aspectos particulares em cada obra, embora em algumas escolas literárias, como, por exemplo, o Parnasianismo, se levava em consideração, prioritariamente, a estrutura frente ao conteúdo, ou a "alma” da obra. Nesta fresta, Oliveira assevera que,

Certos textos podem exigir a contribuição de mais disciplinas, como a estética, que investiga a dimenção filosófica do fenômeno artístico, ou a linguística, voltada para as relações com a linguagem e com os signos verbais. A psicologia, a sociologia, a história da arte fornecem também subsídios indispensáveis, dependendo do tipo de investigação. (OLIVEIRA, 2002, p. 46)

A partir deste pressuposto, a Música, em termos gerais, não difere muito da literatura; sua construção é pautada na teoria musical, e a mesma também é concedida mediante o estudo em seu contexto científico, vale destacar, que, ela é uma das mais próximas irmãs da literatura, principalmente, se pensarmos nas relações poéticas e musicais que existem na Poesia. Na música a utilização/escolha de cada nota musical irá diferenciar uma obra da outra, nos referindo neste ponto as escalas, construção de acordes (tríades, tétrades), melodias e aos arranjos, que possuem suas características e suas intenções que são pré-definidas segundo a harmonia, harmonia esta pensada pelo músico que pode usar vários recursos,

20 "na verdade, fora desse imenso complexo de palavras e vozes parodicamente refletidas, o chão estava sendo preparado nos tempos antigos" (tradução nossa). 
no que diz respeito ao estudo da harmonia musical, para construí-la. Todo este universo se assemelha ao universo das escolhas da composição literária, em que o escritor assim como o músico utilizam as várias possibilidades que ambas as linguagens permitem que eles o façam.

Cada músico possui suas preferências no quesito de harmonia, escalas e outros adornos que compõem os vários fragmentos da obra como um todo: as notas musicais constituem esses fragmentos, assim como, no caso da linguagem literária, os artigos, preposições, concordância verbal e nominal, as variações linguísticas, as figuras de linguagem, metáforas, as alegorias, questões temáticas, etc. Na música elas são o que caracterizam uma obra dentro de determinada época, permitindo reconhecer o estilo de um determinado compositor. Pode-se dizer que, o escritor e o compositor são irmãos de criação no contexto de suas obras, pois, a caracterização que um utiliza é semelhante à do outro.

Steven Paul Scher salienta em seu ensaio: Literatura e Música de 1982²1, que "Música e Literatura compartilham sua origem é uma noção tão antiga quanto os primeiros sinais da consciência estética. Mesmo uma rápida olhada na evolução das artes confirma que 'as histórias de ambos permaneceram, de várias maneiras, mutuamente contingentes'22"، (SCHER, 2004. p. 172). No que diz respeito a estética, percebemos que, após o Romantismo embaralhar todos os gêneros em um enorme mosaico, novas possibilidades foram criadas, ampliando não apenas a visão em relação aos gêneros literários, como também, a criação de novas estéticas. Lia Tomás, na obra Ouvir o logos, salienta algo que está na mesma esteira teórica supracitada, a saber:

A relação entre elas, música e literatura é mais profunda, pois, sendo a voz humana o mais primitivo instrumento musical, a música surgiu do canto e, no canto, o conteúdo é a poesia declamada melodiosa-

\footnotetext{
${ }^{21}$ Para maiores informações vide: Literature and Music (1982) In: Word and Music Studies - Essays on Literature and Music (1967 -2004) by Steven Paul Scher. Edited by Walter Bernhart and Werner Wolf. New York. 2004.

${ }^{22}$ Music and literature share their origin is a notion as old as the first stirrings of aesthetic consciousness. Even a cursory glance at the evolution of the arts confirms that 'histories of both have remained in many ways mutually contingent.
} 
mente. Ao produzir instrumentos musicais, o homem procurou imitar a voz. Só em uma etapa a posteriori surgiu a música absoluta, isto é, completamente dissociada de qualquer mensagem literária. (TOMÁS, 2005, p. 11)

Segundo a fala de Tomás, é possível constatar que os caminhos que ambas percorrem são paralelos. No caso do conto Machadiano, a relação pode ir além da especulação de que as marcas da inter-relação com a música sejam apenas para o mero andamento de leitura, é possível perceber, uma relação dialogal mais profunda do que se parece, partindo do olhar cuidadoso com a estrutura, com a questão temática e com a forma que é realizada o diálogo com a arte musical, sem mencionar as questões estéticas e simbólicas. Um aspecto perceptível é o cuidado que Machado possui em organizar o conto com um espectro de uma forma sonata.

O termo Sonata, nos remetendo à origem do termo: Sonata - do Latim: Sonare. Música feita para soar/propagar o som. Isso resgata a ideia de música instrumental, que era em oposição à Cantata (música feita/composta para ser cantada). O que mais chama atenção e possibilita que vejamos a relação é que, normalmente, a sonata era uma composição para instrumentos solistas, no caso a personagem principal, geralmente, Piano (em alguns casos Violino), estruturada em três movimentos (se retoma a ideia do terceto - pensando na estrutura dos personagens uma mulher e dois homens).

Vale a pena destacar que, a forma tradicional que é: exposição, desenvolvimento e reexposição. Esta estrutura é, em termos, como Machado de Assis apresenta seu conto. Isso é significativo, pois, evoca alguns conceitos básicos da constituição da forma sonata, porém, em formato adaptado de/para conto, a saber: Tema I Tema II :| | Desenvolvimento Tema I Tema II Coda | |. Segundo, Henrique Autran Dourado,

Forma sonata (ing. Sonata form; al. Sonaten-form) Estrutura consolidada no Classicismo, aplica-se a um movimento ou peça como uma FORMA TERNÁRIA evoluída. Consiste, basicamente, de três seções (exposição, desenvolvimento e recapitulação), à qual podem ser acrescentados elementos introdutórios e conclusivos (introdução e CODA, respectivamente). O modelo da forma sonata consolidou-se de tal maneira na música ocidental que, mesmo com o advento do ATONALISMO e das técnicas modernas, continuou a ser 
frequentemente empregado durante o século XX entre compositores como Hindemith e Shönberg, por exemplo). (DOURADO, 2008, p. 138)

Se se levar em consideração o mencionado, é possível enxergar que, a relação da tessitura textual está entrelaçada a alguns nós que amarraram o texto literário. Os nós são as terminologias e expressões que adornam a musicalidade das palavras, como também, a relação composicional sem se esquecer da questão da resolução do enredo, em espécie de um campo harmônico de palavras, neste ponto, retomamos antes de finalizar, a fala de Bakhtin, em que afirma, "only knowledge of a language that possesses another mode of conceiving the world can lead to appropriate knowledge of one's own language"23 (BAKHTIN, 1981, p. 62).

Podemos, seguindo o pensando de Bakhtin, entender que, o esqueleto narrativo em que foi organizado o conto possui em suas intersecções elementos do universo da música, que possibilitam o diálogo com a obra literária. A partir desta relação é possível enxergar as intersecções e a relação, praticamente, híbrida que se consolida o conto.

\section{Lá, lá, lá...}

“Trio em lá menor" é um conto separado em quatro momentos, I Adagio cantabile, II Allegro ma non troppo, III Alegro appassionato e IV Minueto. A análise de todas as quatro partes foi realizada, separadamente, pois, se tornou mais fácil entender como as ações e as amarras textuais foram realizadas, assim como, a organização dialógica das linguagens. O conto desde o próprio título já possui elementos musicais. Dentro do universo da Teoria musical o tom de - Lá menor (Am) - é a relativa menor de Dó Maior (C), a escala perfeita

23 "Somente o conhecimento de uma língua que possui outro modo de conceber o mundo pode levar ao conhecimento apropriado da própria língua” (Tradução nossa). 
maior ${ }^{24}$. Isto possui inúmeras implicações, no que tange a teoria musical, de forma específica, está ligado as questões do campo harmônico e o diálogo direto com as questões do enredo.

Ao iniciar análise pelo título, é possível perceber que esta referência pode ser interpretada, inicialmente, de duas formas. Primeiro, é ver que este Lá menor (Am) é a relativa menor da escala de Dó Maior $(\mathrm{C})$ e devido a isso existem intensões (musicais), e, diga-se de passagem, extensões, ou seja, delimita, de certa forma, até onde se pode ir no que concerne as questões de resolução do campo harmônico, como também, a questão da organização dos arranjos, pensando de forma mais orgânica.

As intensões são as notas características da escola, elas dão a ela sua especificidade sonora. O som combinado a partir formação de tríades e tétrades, isso é estudado dentro da teoria musical quando se estuda formação de acordes e campo harmônico. Encontra-se entrelaçado em primeiro plano com uma ideia geral da estrutura do conto, e em segundo plano, com as questões do desenrolar do enredo. Neste sentido, inicialmente, pode-se pensar nesta formação paralela à construção do enredo do conto, seria uma das possibilidades. Uma segunda possibilidade é enxergar que a ideia do trio pode estar relacionada a serem três - Lá menores. Cada qual tentando construir diálogo com o outro, esta segunda opção não nos parece a mais plausível, mas, ainda sim, seria possível certa interpretação, principalmente, se explorarmos os aspectos de cunho irônico do texto.

À ideia de repouso, que se tem na música, passa para o segundo plano. Isto quer dizer que, este repouso é o momento que se tem estabilidade no som, basicamente, uma resolução em toda a linha melódica, o que equivale no enredo a estabilidade das relações dos personagens. No caso do conto machadiano, a visão da construção de uma harmonia seria mais bem definida, levando-se em consideração a formação de três pressupostos mu-

${ }^{24}$ É assim chamada, pois, é a única escala que não possui acidentes em sua clave. Sendo que todas as outras, adquirem os acidentes, exatamente, para acompanharem sua estrutura, ou shape. 
sicais iguais dentro do enredo, no caso, os três personagens que estão entrelaçados na construção da narrativa do conto, cada qual sendo uma nota da escola maior, que entendemos ser Dó Maior (C), devido ao título do conto.

Em relação ao assunto das escalas musicais Kiefer (1987) salienta que existem tons maiores e tons menores. Os menores são relativos dos maiores, vale ressaltar, que, o fato de ser menor não proporciona privilégios, talvez, desperte uma ideia de relação de hierárquica e tão somente. A relação de ser menor está vinculada no grau da escala que se pode localizar o acorde, em relação ao conto, Lá menor (Am), sendo o tom menor e Dó Maior (C) sendo o tom Maior. Kiefer ressalta um aspecto que é importante a se levar em consideração; a característica de certo brilho nas harmonias escritas em tons maiores, não somente o brilho, como também, uma sensação de leveza, alegria, quiçá, júbilo.

Os tons menores como é o exemplo de Lá menor (Am), eles são um pouco mais melancólicos, reflexivos, gera certa sensação de pesar, uma leve tristeza ${ }^{25}$. Retomando a ideia do título do conto, podemos entender que, Machado tenha pensado na relação de repouso/resolução da harmonia/enredo salientando que, talvez, apesar dos desencontros e relações truncadas, ela terá um desfecho feliz. Por outro lado, ao se observar o conto, é perceptível que a relação apesar de possível, é realizada de outra forma, quase como se no momento do repouso/relaxamento, Machado colocasse uma nota como destacamos anteriormente, uma quarta aumentada ou uma quinta diminuta, para dar um estranhamento, ou algo semelhante a uma suspensão, algo que deseja ser resolvido, mas, não o é.

“Trio em lá menor” narra o que poderia ser enxergado como uma história de $\operatorname{amor}^{26}$, entretanto, não chega a se concretizar. É, exatamente, neste ponto, que é possível

\footnotetext{
25 Uma tristeza-reflexiva no sentido se pensar a respeito de algo. Talvez, mas, não ariscaríamos afirmar, algo próximo, talvez, do melancólico, elemento substancial da ideia do mal-do-século.

${ }^{26}$ Não chega a se consolidar como uma estória de amor, pois, o elemento irônico o qual Machado de Assis insere, no caso, a indecisão, provoca toda uma contorção na narrativa, levando a crer em um final, mas, se consolidando outro. Este elemento é um elemento chave, por exemplo, para que a ideia de suspensão se consolide, como é possível ser consolidada na música, quando não se realiza a descanso, ou a resolução da harmonia em uma nota que passe a sensação de repouso.
} 
perceber o "desarranjo". Em termos, pode-se comparar ao acorde que provoca o estranhamento em quem escuta uma canção que vem sendo executada com brilho, leveza, beleza, felicidade e com uma guinada abrupta aparece um som (acorde e/ou nota) que quebra todo o arranjo realizado anteriormente, algo que poderíamos chamar, talvez, de um trítono ${ }^{27}$. Este diabolus em musica está relacionado com a questão do Leimotiv, ocasionando, em certa medida, a completude da inquietação, da indecisão da personagem.

Ao analisarmos como se apresenta o leitmotiv, podemos considera-lo como mais um dos elementos que constroem o diálogo entre as artes. A ideia, do motivo condutor do conto, pode ser interpretada como: um vínculo, algo quase orgânico entre as duas artes. Vale destacar que, o leitmotiv se constitui, inicialmente, um elemento musical, que, a posteriori se consolida na literatura.

A indecisão se torna marca autentica da personagem principal, Regina, ao passo de não saber escolher entre os dois cavalheiros, e, não somente isto, este se torna, por exemplo, o porquê de ela ficar orbitando entre dois astros. O leitmotiv, se projeta dentro do conto de maneira semelhante ao que se projeta dentro de uma peça musical, ou seja, ele se compõe como tema, melódico, se se pensar diretamente na personagem principal, ou harmônico, se pensar-se na ideia do trio - ou tríade. Além disso, sendo um trio em Lá menor (Am) resgata, além da ideia de ser a relativa menor da escala de C (Dó Maior), a própria constituição da tríade que forma o acorde de Lá menor (Am) ${ }^{28}$.

De forma sintética, o conto narra à história de Maria Regina, é um conto alegórico que traz à baila a indecisão de uma mulher, que não consegue escolher entre dois homens: Maciel e Miranda. Na visão da personagem, Maciel se apresenta energético, cheio de vida alegre, mas que logo se transforma em futilidade, pois, é apegado às pequenezas que a ela

\footnotetext{
${ }^{27}$ Trítono (it. Tritono; fr. Triton; ing. Tritone; al. Tritonus) Intervalo de quarta aumentada (ex.: dó-fá sustenido), formado por notas distantes entre si três tons inteiros (dó-fá sustenido). A dissonância do intervalo provocou celeuma: na música religiosa, durante o Renascimento, chegou a ser proibido pela Igreja, razão pela qual era chamado de Diabolus in Musica. (Dourado, 2008, p. 340).
}

${ }^{28}$ A tríade em questão são as notas A - C - E, estas formam o acorde de Lá menor (Am). 
não agrada em nada, como, por exemplo, fofocas e modas. O segundo, Miranda, um homem de mais idade, portanto, mais sério. O segundo não possui a vivacidade do primeiro, mas, é uma companhia de mais conteúdo, que não causa desconforto nem tédio. O conto vai relatar todo o processo da composição desta "história de amor". No final, Regina se perde nos devaneios e sonhos, em que vê e se constrói como metáfora de sua situação.

A ideia de metáfora está relacionada, principalmente, a ironia, devido Maria Regina não conseguir escolher um dos pretendentes e ficar orbitando em algo que podemos intitular como limbo, por fim, ao enxergar a junção deles em uma forma híbrida de um terceiro que não existe: "Tratou de combinar os dois homens, o presente com o ausente, olhando para um, e escutando o outro de memória; recurso violento e doloroso, mas tão eficaz, que ela pode contemplar por algum tempo uma criatura perfeita e única" (ASSIS, p. 150). Ela cria em sua mente algo metafórico, na medida em que esta ambiguidade existencial é firmada, a protagonista sentencia a desarmonização de tudo que vem sendo, progressivamente, resolvido. Partindo do pressuposto dos personagens personificados como notas musicais, percebemos que, as notas, ou as relações delas, fazem parte da função de provocar a tensão da harmonia-enredo e da harmonia do enredo.

Regina termina por ouvir uma voz fantasmagórica que lhe diz: "É tua pena, alma curiosa de perfeição ${ }^{29}$; a tua pena é oscilar por toda a eternidade entre dois astros incompletos, ao som desta velha sonata do absurdo: lá, lá, lá” (ASSIS, p. 153, grifo nosso). É interessante observar que, da mesma forma que o narrador constrói seus personagens com caracterizações centradas nas escolhas lexicais, não se pode esquecer que é o autor quem tem o domínio sobre as escolhas. A voz fantasmagórica é a voz de um narrador onisciente e heterodiegético, assim, as ações de Regina são entendidas como, ações que refletem a qualidade que gera a tensão em formato de indecisão, diante disso, a personagem não pos-

\footnotetext{
${ }^{29}$ Curiosa de perfeição retoma, de forma interessante, por exemplo, a questão da escala de Dó Maior (C) ser considerada a escala perfeita, sem acidentes. O desejo das outras escalas de se assemelharem a ela, de certa forma, e isso é comprovável dentro da teoria musical, produz os acidentes, que por sua vez, provocam tensões dentro das relações das notas.
} 
sui forças para se projetar, realizando seja como for, algo que esteja próximo a uma resolução, em outras palavras, ela acaba em órbita, não escolhendo nenhum. Neste ponto, destacamos a sensação de suspensão ${ }^{30}$ a qual uma harmonia não resolvida transmite. Vale destacar também, que, esteticamente - lá, lá, lá, nos transmite a ideia de incompletude, algo que se encontra sempre à frente, mas, que ao passo que se aproxima torna a distanciar-se, um quase elemento utópico.

Dentro da teoria musical, o tom de Dó Maior (C) é considerado a escala perfeita maior, todas as outras escalas buscam se tornarem como ela em estrutura. Disso, ocorrem os acidentes, que dentro da Música são grafados como: sustenidos e bemóis. No caso do conto, podemos enxergar a ideia destes acidentes, por exemplo, como, a indecisão, a insatisfação entre outros sentimentos e pensamentos da protagonista, em que impedem, de alguma forma, o desejo pela perfeição.

Os acidentes são notas ímpares dentro do contexto de cada tom, pois, são elas que marcam a diferença sonora que é possível escutar entre as escalas, como, por exemplo, a escala de Dó maior (C) não possui acidentes, assim sendo, ela é considerada a escala perfeita. Se pensar na escala de Sol Maior $(G)$, ela terá um acidente em Fá (F), que se tornará um Fá menor sustenido (Fm\#). Esta nota é a marcar/registro que mostra que a harmonia não está no tom de Dó Maior (C), mas sim, no de Sol Maior (G).

A alma curiosa de perfeição, que o autor coloca como sendo de Regina, pode estar relacionada à está relação musical de alinhamento a escala perfeita. A busca por este alinhamento é o trajeto/enredo do próprio conto e todas as relações truncadas possíveis, de se enxergar no trajeto da protagonista: “convenho que é abominável, mas não posso alterar a feição das coisas, não posso negar que se os dois homens estão namorados dele, ela não o está menos de ambos" (ASSIS, p. 145).

A ideia dos astros incompletos retoma a relação da busca da completude. Ao relacionar o mencionado a música, o repouso que é encontrado quando se toca um acorde de

${ }^{30}$ A sensação de algo precisa ser resolvido, ou estabilizado. 
resolução da harmonia, no caso de Dó Maior (C), o próprio Dó maior (C) seria uma opção, ou seja, o processo de ir e andar uma oitava de notas, retornando e assentando sua resolução. Outra possibilidade seria pensar na relação no grau dominante (Sol maior/ G) ou superdominante (Lá menor / Am) retornando a tônica, criando assim, a ideia de contração e relaxamento ${ }^{31}$. O que em termos gerais é o que acontece entre os três astros "Ao pé da cama, Maria Regina reconstruía agora tudo isso, a visita, a conversa, a música, o debate, os modos de ser de um e do outro, as palavras de Miranda e os belos olhos do Maciel. Eram onze horas, a única luz do quarto era a lamparina, tudo convidava ao sonho e ao devaneio.

Maria Regina, à força de recompor a noite, viu ali dois homens ao pé dela, ouviu-os, e conversou com eles durante uma porção de minutos, trinta ou quarenta, ao som da mesma sonata tocada por ela: lá, lá, lá ...” (ASSIS, p. 146, grifo nosso). A conversa se alonga, nos parece, pelo motivo da busca de adaptação, ou seja, a tônica da relação, Regina, busca alguma maneira, considerando as qualidades e defeitos, comparáveis aos acidentes musicais, se acertar para que consiga, ainda não se sabe como, a perfeição.

O primeiro momento, ou melhor, a primeira parte é a Adagio cantabile. Ela é o primeiro subtítulo, logo de início o autor já destaca a problemática, ou seja, o truncamento do contato com os dois homens, os dois após a visita estão enamorados por Regina, ela em seu quarto fica reflexiva pensando em ambos os pretendentes. Neste cenário existe certa musicalidade marcada pela melodia da sonata que, por ela foi executada ao piano momentos antes na sala e durante a visita: "Maria Regina conversou alegremente com eles, e tocou ao piano uma peça clássica, uma sonata, que fez a avó cochilar um pouco. No fim discutiram música" (ASSIS, p. 146, grifo nosso). Nos parece que, a música é sempre o pano de fundo, pois, de ' $n$ ' maneiras o escritor consegue encaixá-la para que ela sempre esteja orbitando, mesmo que forma fantasmagórica, o espectro total do conto.

Pensando na nomenclatura que Machado coloca nesta primeira parte, Cosme (1959) destaca que, Adagio refere-se ao andamento da composição musical. No caso deste

${ }^{31}$ Este conceito é primordial dentro do universo da arte musical. 
termo é um andamento mais lento. Em outras palavras, são as batidas por minutos (BPM) que marcam a execução do trecho musical. Esta relação pode ser pensada, assim como o Maestro vê a nomenclatura e sabe como deve se portar diante o trecho, o leitor, principalmente o leitor Machadiano, que não é ou não deveria ser um leitor ingênuo, pode levar em consideração estas marcas para realizar a leitura, pensando no conto como uma forma sonata, o processo de reconhecimento de Maria Regina, com os dois pretendentes, está intimamente ligada a esta ideia musical, o andamento lento pode ser visto como um preludio para o que vem a seguir.

Ainda na primeira parte, pensando principalmente, em uma peça musical é a parte que se mostra o tema, isto é, a melodia que vai ser desenvolvida, por exemplo, a introdução, principalmente, na música clássica é um movimento não muito longo, mas, executado com moderação apresentando as variações sonoras e os fraseados melódicos que serão o fio narrativo da composição, este fio narrativo chamamos de intensão. Na primeira parte, portanto, aparece uma pequena amostra do tema e dos personagens. Kiefer (1987) salienta que uma das características do Adagio é que permite ornamentos.

Os ornamentos são realizados por Machado à medida que ele apresenta a personagem principal, os dois amores (incompletos neles mesmos, e impossíveis de completude com Regina), o contexto e a ambientação, a marca de Regina estar ao piano, a forma que ela executa a sonata e como o som propaga por todo o ambiente cria uma atmosfera musical, ou seja, esta é uma das ideias que se pode destacar como ornamento dentro do conto, principalmente, se se observar que, na medida em que vai progredindo o conto, Machado (podendo ser pensando na figura de Maestro) conduz toda a trama com uma marcação de tempo, de intensões, construindo um todo harmônico que, progressivamente, leva o leitor a enxergar a música e a literatura caminhando de mãos dadas para o mesmo destino. É possível entender o mencionado na seguinte passagem: "A avó, prevendo a sonata, aparelhou a alma para alguns cochilos [...] Calou-se no fim de alguns minutos. A sonata veio, no meio de uma conversação que Maria Regina achou deleitosa, e não veio senão porque ele lhe pediu que tocasse; ele ficaria de bom grado a ouvi-la" (ASSIS, p. 151). 
Neste sentido, pode-se pensar que, de acordo com os tópicos existi uma resolução do campo harmônico, especialmente, ao passo que se resgata o conceito da forma sonata de acordo que o conto for progredindo, resolução segundo Harnouncourt (1990) é o som (acorde) que finaliza uma peça musical. Ao se ler a primeira parte, é possível perceber, a relação de beleza e vagarosidade apresentado pelo triângulo amoroso, os elementos estão relacionados à ideia do Adagio:

Dez, vinte, trinta dias passaram depois daquela noite, e ainda mais vinte, e depois mais trinta. Não há cronologia certa; melhor e ficar no vago. A situação era a mesma. Era a mesma insuficiência individual dos dois homens, e o mesmo complemento ideal por parte dela. Daí um terceiro homem, que ela não conhecia (ASSIS, p. 152).

Outro fato que se destaca é que neste início/preludio as relações estão harmonicamente estáveis, ou seja, tudo é confortável e destaca uma serenidade que beira o sublime. O trecho: "ouviu-os, e conversou com eles durante uma porção de minutos, trinta ou quarenta, ao som da mesma sonata tocada por ela: lá, lá, lá...” (ASSIS, p. 146, grifo nosso) a parte em negrito se repete durante o conto, uma espécie de afirmação e reafirmação da ideia da sonata, daquela velha sonata, da mesma sonata, a música se apresenta como elemento operador do enredo e da caracterização dos personagens, como também, de quase tudo que está ao seu redor. Neste sentido, a marcação simbólica do material textual está impregnada do universo da música. A terminologia resgata a ideia da arte musical para dentro do conto, o segundo tópico destaca bem a ideia do final do primeiro andamento para o segundo, isto mostra que não é apenas a condução de leitura, a música é elemento fundamental na estrutura e no processo do coser híbrido-textual.

Na segunda parte, Allegro ma non troppo é que, realmente, pode-se ver o início do desenvolvimento da história e da linha que se criada entre a narrativa do conto e a narrativa da peça musical, ou do conto sendo pensado enquanto forma sonata. Alguns fatos que concretizam são, primeiro, Maciel arriscando a sua vida para salvar um menino que de forma desatenta atravessa a rua. Segundo, a carruagem que iria atropelar o menino, carruagem a qual estavam Maria Regina e sua avó. A partir disso, os atributos de Maciel são destacados. 
A protagonista irá reconhecer nele qualidades que irão leva-la a refletir: "Maria Regina perguntava a si mesma onde acharia melhor noivo" (ASSIS, p. 148). Allegro ma non troppo, segundo Wisnik (2004) é um andamento para indicar ao músico a execução da peça, podendo ressaltar a presteza. O destacado pode ser aplicado também no âmbito da leitura, pois, além de estar vinculada as questões do andamento da narrativa a presteza na leitura acentua a terminologia musical.

Segundo Wisnik, em uma tradução livre, seria; “rápido, mas não muito”. Isto quer dizer que, neste momento começa a se criar a pulsação, o ritmo começa a ter suas progressões e marcações mais definidas e acentuadas. Embora, não exista uma regra rígida em relação a esta ideia de: rápido, mas não muito -, uma parte dos músicos utiliza uma pulsação entre 90 e 120 batidas por minuto (BPM). É notável que, este andamento pode ser chamado também de Allegro moderatto. Retomando o texto, a protagonista fica inebriada pela coragem de Maciel e, em seguida, demostra contentamento. Este sentimento pode ser relacionado ao ma non troppo (mas não rápido), isso é perceptível na próxima parte do conto em que o encantamento pelo herói se enfraquece. A saber:

Maria Regina ia descambando da admiração no fastio; agarrava-se aqui e ali, contemplava a figura moça do Maciel, recordava a bela ação daquele dia, mas ia sempre escorregando; o fastio não tardava a absorvê-la. Não havia remédio. Então recorreu a um singular expediente. Tratou de combinar os dois homens, o presente com o ausente, olhando para um, e escutando o outro de memória; recurso violento e doloroso, mas tão eficaz, que ela pôde contemplar por algum tempo uma criatura perfeita e única. Nisto apareceu o outro, o próprio Miranda. Os dois homens cumprimentaram-se friamente; Maciel demorou-se ainda uns dez minutos e saiu (ASSIS, p. 150).

A terceira parte do conto, Allegro Appassionato, é a continuação da visita realizada por Maciel a Regina, este fato ocorre no mesmo dia do ato heroico. A conversa de Maciel e sua avó sobre futilidades despertam em Regina certa indiferença, e o interesse vai se esvaziando gradativamente, a saber:

Maciel era homem, como ele mesmo dizia em francês, três repandu; sacou da 
algibeira uma porção de novidades miúdas e interessantes. A maior de todas foi a de estar desfeito o casamento de certa viúva.

- Não me diga isso! exclamou a avó. E ela?

- Parece que foi ela mesma que o desfez: o certo é que esteve anteontem no baile, dançou e conversou com muita animação. Oh! abaixo da notícia, o que fez mais sensação em mim foi o colar que ela levava, magnífico...

- Com uma cruz de brilhantes? perguntou a velha. Conheço; é muito bonito.

- Não, não é esse.

Maciel conhecia o da cruz, que ela levara à casa de um Mascarenhas; não era esse. Este outro ainda há poucos dias estava na loja do Resende, uma cousa linda. E descreveu-o todo, número, disposição e facetado das pedras; concluiu dizendo que foi a joia da noite.

- Para tanto luxo era melhor casar, ponderou maliciosamente a avó.

- Concordo que a fortuna dela não dá para isso. Ora, espere! Vou amanhã, ao Resende, por curiosidade, saber o preço por que o vendeu. Não foi barato, não podia ser barato.

- Mas por que é que se desfez o casamento?

— Não pude saber; mas tenho de jantar sábado com o Venancinho Corrêa, e ele conta-me tudo. Sabe que ainda é parente dela? Bom rapaz; está inteiramente brigado com o barão...

A avó não sabia da briga; Maciel contou-lha de princípio ao fim, com todas as suas causas e agravantes. A última gota no cálice foi um dito à mesa de jogo, uma alusão ao defeito do Venancinho, que era canhoto. Contaram-lhe isto, e ele rompeu inteiramente as relações com o barão. O bonito é que os parceiros do barão acusaramse uns aos outros de terem ido contar as palavras deste. Maciel declarou que era regra sua não repetir o que ouvia à mesa do jogo, porque é lugar em que há certa franqueza (ASSIS, p. 148-9).

Neste sentido, assim como as paixões, a interpretação por meio da música desta parte destaca o Allegro Appassionato, segundo Kiefer (1987) e Cosme (1959) este é um andamento com certa velocidade na execução, e claro, com um tom mais apaixonado, como o próprio termo já destaca: appassionato. Destaca-se este termo, pois, é um andamento que se move pensando, principalmente, na ideia da paixão, pela forte capacidade de transmitir e despertar o sentimento em quem ouve, no caso, em quem lê.

Neste pedaço os dois pretendentes se encontram no mesmo contexto, "os dois homens cumprimentaram-se friamente; Maciel demorou-se ainda uns dez minutos e saiu, Miranda ficou” (ASSIS, p. 150). Destacamos que a relação com a música além de conduzir 
o ritmo de leitura, resgata o fio solto da parte anterior, Maria Regina estava com o andamento, com o pulsar ritmo-cardíaco alegre, apaixonado. A este respeito resgata-se a fala de Andrade no que concerne o ritmo, que serve tanto para a literatura, leitura, como também, para a música, a saber:

O que a gente pode afirmar, com força de certeza é que os elementos formais (...), o Som e Ritmo, são tão velhos como o homem. Este os possui em si mesmo, porque os movimentos do coração, o ato de respirar já são elementos rítmicos, o passo já organiza um ritmo, as mãos percutindo já podem determinar todos os elementos do ritmo. E a voz produz o som. Desses dois elementos constitutivos da música, o mais rápido a se desenvolver é o ritmo. Fazendo parte, não só da música, mas de poesia e dança também, sendo mesmo a entidade que une essas três artes, e lhes permite se manifestarem juntas numa arte só, é perfeitamente compreensível que ele se desenvolva em primeiro lugar. (ANDRADE, 1953, p. 13)

Dois pontos principais mostram a relação direta que a música tem com esta parte, a primeira: "A sonata veio, no meio de uma conversação que Maria Regina achou deleitosa, e não veio senão porque ele the pediu que tocasse; ele ficaria de bom grado a ouvi-la" (ASSIS, p. 151). A segunda: "e a música ia ajudando a ficção, indecisa a princípio, mas logo viva e acabada" (ASSIS, p. 151). Neste sentido, as marcas dos elementos musicais que são apresentados, separadamente, por Machado de Assis, confirmam de certa forma a existência de uma intencionalidade do autor, em se utilizar dos ornamentos e arranjos musicais, assim como, da teoria musical para conduzir o diálogo entre as duas artes, internamente, no objeto. O Arranjo simbólico do conto se constitui em muito, de um mosaico de elementos que são provenientes do universo da música.

Sendo cada uma das partes representadas de forma desmembrada, os eventos vão se entrelaçando rumo à ideia do repouso, em outras palavras, rumo à finalização do texto, o acorde de - Lá menor (Am), com suas notas A (lá), C (Dó) e E (Mî) se apresentam em campo. Minueto é a última parte do conto. Esta parte se inicia com uma incerteza de tempo transcorrido e, principalmente, a indecisão de Maria Regina. Indecisão que beira a perda de esperança, a saber:

Dez, vinte, trinta dias passaram depois daquela noite, e ainda mais vinte, e depois mais trinta. Não há cronologia certa; melhor é ficar 
no vago. A situação era a mesma. Era a mesma insuficiência individual dos dois homens, e o mesmo complemento ideal por parte dela; daí um terceiro homem, que ela não conhecia. Maciel e Miranda desconfiavam um do outro, detestavam-se a mais e mais, e padeciam muito, Miranda principalmente, que era paixão da última hora. Afinal acabaram aborrecendo a moça. Esta viu-os ir pouco a pouco. A esperança ainda os fez relapsos, mas tudo morre, até a esperança, e eles saíram para nunca mais. As noites foram passando, passando... Maria Regina compreendeu que estava acabado. (ASSIS, p. 152)

O que Regina busca pode ser lido, sem extrapolar as margens do que pode ser abstraído do texto, como o fim da peça musical. A busca pela completude, assim como, as escalas que não são como a escala perfeita maior (C - Dó Maior) precisam se adequar, se modificar, se estranharem em uma mutação até que consiga, de certa forma, uma igualdade artificial a ela. Regina busca está completude e um terceiro aparece, o astro desdobra-se e ela fica vagando entre as duas porções, em busca do sentimento de satisfação (solução/resolução).

A aflição (ou sina) de Regina seria oscilar, por toda a eternidade entre dois astros incompletos. Neste momento, a voz do narrador salienta que, "É a tua pena, alma curiosa de perfeição; a tua pena é oscilar por toda a eternidade entre dois astros incompletos, ao som desta velha sonata do absoluto: lá, lá, lá...” (ASSIS, p. 153).

Minueto, segundo Cosme (1959) é uma peça composta em compasso de três por quatro, ou seja, um compasso ternário. Ainda segundo o mesmo autor, ele diz que o Minueto surgiu em 1650 e servia para acompanhar uma dança francesa de mesmo nome na corte do rei Luís XIV. Vale ressaltar que, esta estrutura de compasso é também chamada de Valsa ${ }^{32}$. Pensando na estrutura: ternário, é possível perceber a manutenção que o autor constrói para manter os três elementos dentro do jogo narrativo, sempre ancorado no mosaico simbólico musical.

\footnotetext{
${ }^{32}$ Entendemos então que, Machado em sua genialidade consegue coser no final de tudo, uma "Valsa" dentro do objeto que divide o mesmo espaço. Neste sentido, a figura da Valsa é estabelecida e procura fechar com chavede-ouro, o que a personagem buscava o repouso. Repouso este que pode ser interpretado de maneira tanto musical, como também, literário.
} 
Retomando a análise ao fio narrativo-textual, por mais que eles estejam, de certa forma, orbitando ao redor do mesmo astro, eles apresentam a incompletude e buscam a solução, o que resgata a ideia da resolução do campo harmônico. A ideia da estrutura da valsa está relacionada à figura do triângulo amoroso, está relacionado também, a ideia de Regina ficar orbitando entre dois astros, se tornando o terceiro elemento, ou movimento desta peça musical. Ressalta-se que, Minueto é uma composição completa e se difere da ideia dos outros andamentos.

Ao se pensar no último momento do conto, é possível se perceber, que, a Valsa está relacionada à ideia da forma sonata, que se consolidou o movimento no final do conto, ou seja, ela é tomada nas diferentes direções que, ora vão para um lado, ora vão para outro, é perceptível que a música é elemento fulcral para o conto, neste sentido, a música está para a literatura como a literatura está para música, por mais que haja um relação hierárquica, os conceitos musicais completam e ampliam o conto como um todo. O vai-e-vem que a vida de Regina realiza, pensando em sua inconstância, constituem, substancialmente, os encadeamentos de ideia e acontecimentos na vida da protagonista, a saber; "Tinha lido de manhã, em uma notícia de jornal, que há estrelas duplas, que nos parecem um só astro. Em vez de ir dormir, encostou-se à janela do quarto, olhando para o céu, a ver se descobria alguma delas; baldado esforço. Não a descobrindo no céu, procurou-a em si mesma, fechou os olhos para imaginar o fenômeno. [...] Maria Regina viu dentro de si a estrela dupla e única. E ela queria o astro esplêndido. Quando abriu os olhos e viu que o firmamento ficava tão alto, concluiu que a criação era um livro falho e incorreto, e desesperou" (ASSIS, p. 152-3).

\section{Considerações finais}

Ao se pensar no caminho percorrido, é perceptível que Machado de Assis conseguiu se utilizar da música de forma peculiar. Este conto como alguns outros, já mencionados no trabalho, compõe uma bibliografia do autor que mostra o cuidado e a sensibilidade que ele possuía, no que concerne à forma de enxergar não somente o método, como mencionado, 
mas, o próprio olhar para a composição como um todo, isso fica claro, após a leitura cuidadosa dos detalhes que o autor deixou para os leitores de seus romances e seus contos.

A área de estudos da literatura com a música, no caso deste conto da música na literatura, possui muitas veredas para serem exploradas, começar a percorrer estes caminhos com um conto Machadiano foi uma oportunidade muito interessante de enxergar como estas duas artes criam um diálogo fértil e plural, frutífero em suas extensões orgânicas e estéticas. Ainda a respeito da peculiaridade do conto, é perceptível que o autor buscou não apenas uma relação superficial com a música, mas, conseguiu de forma suficiente entrelaçar as duas em um objeto artístico, que possui ainda muitos elementos a serem explorados, assim, terminamos nossa análise com as seguintes palavras de Regina, "Não acha sublime? Perguntou ela, no fim” (ASSIS, p. 150).

\title{
BETWEEN FRITS AND EDS: LITERATURE AND MUSIC IN MACHADIAN TALE
}

\begin{abstract}
The present work analyzes signs of dialogue between literature and music in the short story entitled: "Trio em lá menor", by Machado de Assis. The analysis aims to understand how elements of music theory, such as nomenclatures and concepts, as well as the ideas of harmonic field resolution, are intertwined with the writing of the text, surpassing the idea of the mere justification of reading progress of the short story, constituting an integral part of the textual material. The relationship between the sister arts in the text provides a kaleidoscope of possibilities, it seems to us that the author made use of harmonic field resolution ideas, among others from the musical universe, to compose, or rather, write his text, creating a peculiar atmosphere to the short story.
\end{abstract}

KEYWORDS: Literature; Music: Machado de Assis; Short story.

\section{REFERÊNCIAS}

ANDRADE, Mario de. Pequena história da música. São Paulo: S.A. 1953.

ASSIS, Machado de. Trio em lá menor. In: ROCHA, João C. de Castro (Org.) Contos de Machado de Assis: Literatura e Música. Editora Record. Rio de Janeiro. p. 145- 153. 2008. . Trio em lá menor. In: Várias histórias. São Paulo: Mérito, 1961, p. 125- 138. . Memorial de Aires. Obra completa, Rio de Janeiro: Nova Aguilar, 1994. . Esaú e Jacó. Obra completa, Rio de Janeiro: Nova Aguilar, 1994. 
slavic series; no. I. Translation of Voprosy literatury i estetiki. Printed in the united states of America, 1981.

COSME, Luís. Introducão à música. 2. ed. Porto Alegre: Globo. 1959.

DOURADO, Henrique Autran. Dicionário de termos e expressões da música. São Paulo: 34, 2004.

HARNONCOURT, Nikolaus. O discurso dos sons. 2. ed. Rio de Janeiro: Jorge Zahar, 1990.

HORN, Sonia Regina Nascimento. Heteroglossia bakhtiniana: estratégias discursivas no texto para crianças. Disponível em: http://www.filologia.org.br/viiicnlf/anais/cader no05-13.html. Acesso em 20 de out. 2017.

KIEFER, Bruno. Elementos da linguagem musical. 5. ed. Porto Alegre: Movimento, 1987.

OLIVEIRA, Solange Ribeiro de. Literatura e música: Modulações pós-coloniais. São Paulo: Perspectiva. 2002.

SCHER, Steven P. Essays on literature and music (1967-2004). New York. 2004.

TOMÁS, Lia. Música e filosofia: estética musical. São Paulo: Irmãos Vitale. 2005.

TOMÁS, Lia. Ouvir o lógos: música e filosofia. São Paulo: UNESP, 2002.

VERISSIMO, José. História da literatura brasileira - de Bento Teixeira (1601) a Machado de Assis (1908). 3. ed. Rio de Janeiro: José Olympio, 1954. (Col. Documentos brasileiros, no 74). Cap. XIX, Machado de Assis p. 343-359.

VIEIRA, Ernesto. Diccionario musical: ornado com gravuras e exemplos de música. 2. ed. Lisboa: Typ. Lambertini - Fornecedor da casa real, 1899.

Recebido em: 10/03/2020. Aprovado em: 29/05/2020. 